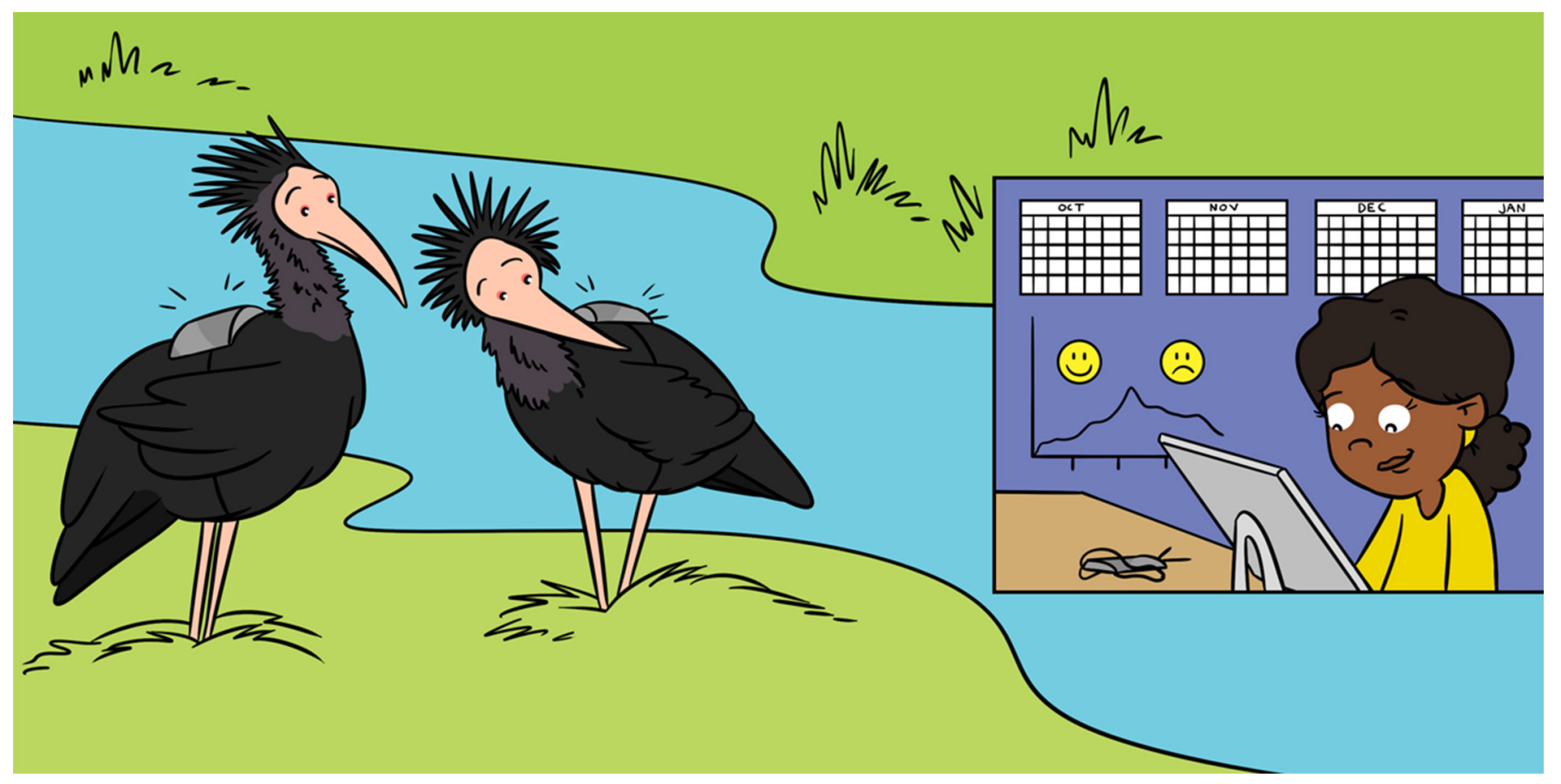

\title{
TRACKING BIRDS: HOW A LITTLE BACKPACK COULD AFFECT THE LIFE OF A WILD BIRD
}

\section{Verena Puehringer-Sturmayr ${ }^{1,2}$, Francesca Hemetsberger ${ }^{1}$ and Didone Frigerio ${ }^{1,2^{*}}$ \\ ${ }^{1}$ Konrad Lorenz Research Center for Behavior and Cognition, University of Vienna, Vienna, Austria \\ ${ }^{2}$ Department of Behavioral and Cognitive Biology, University of Vienna, Vienna, Austria}

\section{YOUNG REVIEWERS:}
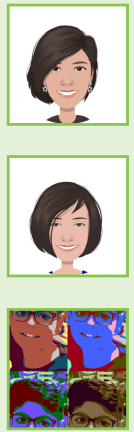

ISABEL

AGE: 9

MARGARIDA

AGE: 12

SHASHIPREE-

THAM

AGE: 13
Do you know it is possible to track the movement of birds wherever they go? GPS-transmitters, which look like little backpacks, can be carried by birds, allowing their movements to be monitored over both long time periods and great distances. However, before equipping birds with these "little backpacks," it is important to investigate if and how the GPS-transmitters affect the birds' behavior and bodily processes, for example their stress levels. To find this out, we observed the behavior of a group of northern bald ibises that were tagged with GPS-transmitters and compared them with a non-tagged group. We did not find any behavioral differences among the tagged and the control birds, but 1 month after tagging, the levels of stress were higher in the tagged group. Since the northern bald ibis is an endangered species, it is very important for researchers trying to protect the ibis to be sure that GPS-tagging does not increase the stress level of this animal. 


\section{GPS-TRANSMITTERS}

Miniature devices, attached to an animal, that use the Global Positioning System (GPS) - which is composed of GPS satellites transmitting signals to devices on the earth-to determine the location of tagged animals.

\section{TAGGING}

Birds were fitted with GPS-transmitters that were fixed to the back of the birds using a harness similar to a dog harness.

\section{DORSAL FEATHER}

PREENING

Cleaning the area around the GPS-transmitter with the bill.

\section{CORTICOSTERONE}

The major stress hormone in birds. Corticosterone levels can be measured in the blood or the droppings The amount of corticosterone in the droppings is proportional to that in the blood and is thus a good measurement to assess the stress response of an animal.

\section{HOW CAN WE FOLLOW MOVING ANIMALS?}

Modern technology has made it possible to track the movement of birds wherever they go. You can always know a bird's position even if it flies away or migrates. GPS-transmitters are instruments that use the Global Positioning System (GPS) to determine the location of tagged birds. Such GPS-transmitters are carried by birds as "little backpacks" and they allow us to monitor the birds over both long periods of time and great distances [1].

However, the effects of tagging on the behavior of birds are still not completely understood. Imagine you have to carry a backpack for several days, months, or even for your entire life. Do you think this would affect the quality of your life? As you can imagine, this information might be especially important when monitoring endangered species, when planning strategies to conserve endangered species, and when reintroducing species into a habitat [2]. Therefore, it is critical to identify and investigate the potential effects of GPS-transmitters on birds.

In our study, we investigated the effects of GPS-transmitters on the behavior and bodily processes of a group of northern bald ibises (Latin name Geronticus eremita). We focused on short-term (the first days after attachment) and middle-term (11 weeks after attachment) effects on the birds, especially on specific behaviors, such as general body maintenance behavior (like cleaning the plumage) and dorsal feather preening, which is cleaning the area around the GPS-transmitter with the bill. We also studied the ibises' social behavior, both friendly and aggressive. Finally, we considered two further parameters: (i) the body weight of the birds, and (ii) the levels of a hormone called corticosterone in the birds' feces (called droppings). Corticosterone is used to measure the stress level of the birds. To be very precise we measured "excreted corticosterone metabolites," but for ease of understanding we will talk about corticosterone in the text.

\section{WHERE DID WE CONDUCT THE STUDY AND HOW DID WE DESIGN THE EXPERIMENT?}

The animals we studied belong to a colony of free-ranging northern bald ibises, which was established at the Konrad Lorenz Research Center, in the valley of the river Alm in the northern part of the Austrian Alps, in 1997 [3]. The birds are used to the presence of humans and each ibis is marked with an individual combination of colored leg rings for identification. At the time of data collection, the colony consisted of 45 individuals, including adult and juvenile birds. We chose 24 adult birds, ranging from 2 to 18 years old, to observe in our study. The birds experienced different procedures: handling, weighing, and tagging. The handling procedure included catching and holding the birds. The birds were caught by hand or by using a hand net and we 
Figure 1

Two northern bald ibises, one of which carries a GPS-transmitter. Picture credit: Verena Pühringer-Sturmayr

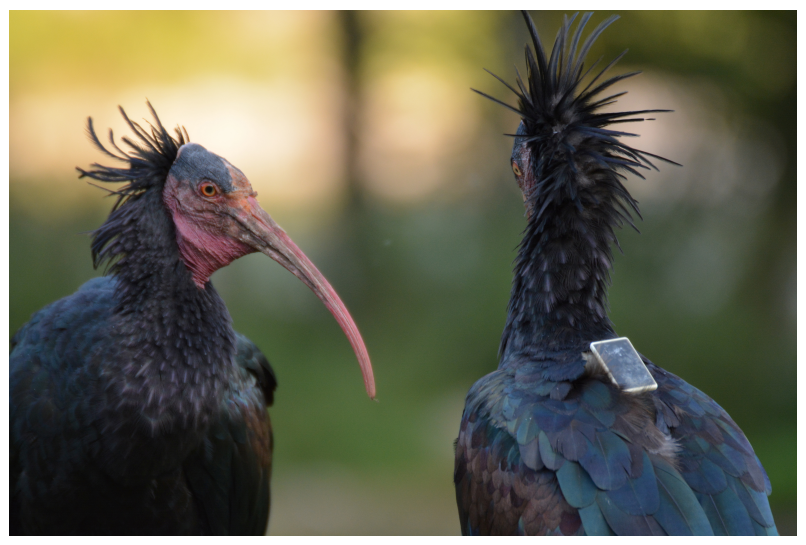

Figure 1

avoided chasing them. For the weighing procedure, the ibises' body weights were measured by putting each bird in a bag and weighing it with a hanging scale. This is an important measurement, as the GPS-transmitter weight should not exceed $3 \%$ of the body weight of the bird [4]. As you can imagine, a heavier GPS-transmitter could make it difficult for a bird to fly normally. The tagging procedure consisted of placing the transmitter in a stable position on the bird's body. Depending on the procedures they experienced, the birds were randomly divided into three groups: (i) transmitter group: 8 birds experienced the handling and weighing procedures and were equipped with GPS-transmitters on their backs (Figure 1); (ii) handling group: 8 birds experienced the handling procedure only; and (iii) control group: 8 birds did not experience any procedures and were only observed.

\section{HOW DID WE TAG THE BIRDS?}

Animals in the transmitter group were fitted with GPS-transmitters that were fixed to the back of the birds using a harness similar to a dog harness. The harnesses were handmade to ensure a perfect fit for each bird, since there can be differences in body measurements. Animals in the handling group were held on the lap of a scientist for the same amount of time as the tagging procedure lasted. Animals in the control group were observed but not handled. Catching the birds, attaching the transmitters, and releasing the birds took $\sim 18$ min per bird.

\section{WHAT DATA DID WE COLLECT AND HOW?}

From October to January, all birds in all groups were observed before, during, and after the tagging and handling procedures. We focused on general body maintenance behavior (preening, scratching, shaking, fluffing, stretching, sleeping, resting, and bathing in the sun or water), dorsal feather preening (cleaning the area around the GPS-transmitter 
with the bill), locomotion (walking, short distance flights), and foraging (drinking, feeding, poking with the bill in the soil), as well as the frequency of friendly and aggressive interactions with other ibises (for a detailed description of the behaviors of the northern bald ibis see [5]).

Additionally, we collected droppings from the individual birds to determine the levels of corticosterone in the droppings, since we know that the amount of this hormone in the droppings is proportional to the level in the blood [6]. Measuring the concentration of corticosterone in droppings is a safe and easy method to determine the stress levels of the birds. Collecting droppings can be very demanding, as the observer has to wait until the animal defecates. The droppings were frozen within $2 \mathrm{~h}$ after collection and sent to our colleagues in Vienna for analysis.

\section{WHAT DID WE EXPECT TO FIND?}

We predicted that the strongest effects on the ibises' behavior would be observed shortly after the tagging procedure. We thought the birds might feel uncomfortable with the GPS-transmitters, which can change the position of their feathers, and we thought the birds would increase their body maintenance behavior. We also predicted that tagged individuals might be more stressed than the control group, which would result in higher concentrations of corticosterone in droppings shortly after the attachment of the GPS-transmitters. However, we predicted that the birds' behavioral patterns and concentrations of corticosterone would return to normal within two and a half months after tagging. We also thought it was possible that individuals in the transmitter group might lose weight, since they had to spend more energy to carry the backpacks.

\section{WHAT DID WE FIND OUT AND WHAT DO OUR RESULTS MEAN?}

Our actual results differed slightly from our predictions. We found that the attachment of GPS-transmitters on free-flying northern bald ibises did not really cause changes in the birds' body maintenance behaviors right after tagging (Figure 2). These outcomes, which contradicted our expectations, allowed us to conclude that the harness-attached GPS-transmitters in this study did not have a negative impact on the ibises' body maintenance behaviors. Furthermore, tagging did not change locomotion and foraging behavior in the birds.

However, we did see that tagging affected the ibises' behavior toward other ibises. Friendly behaviors decreased in the transmitter group after the attachment of the GPS-transmitters, whereas the handling and control groups showed no changes in behavior. 
Figure 2

Patterns of two behaviors, dorsal feather preening and body maintenance behavior (preening, scratching, shaking, fluffing, stretching, sleeping, resting, and bathing in the sun or water) for transmitter, handling, and control groups of northern bald ibises. Behaviors were measured at different phases of the observation period, shown on the $\mathrm{x}$-axis. The durations (sec) of the behaviors are shown on the left and right $y$-axis. You can see that the three experimental groups follow the same pattern in showing both behaviors. Thus, both behaviors did not change because of GPS-transmitter attachment. We conclude that the attachment of GPS-transmitters had no negative effect on body maintenance behaviors.

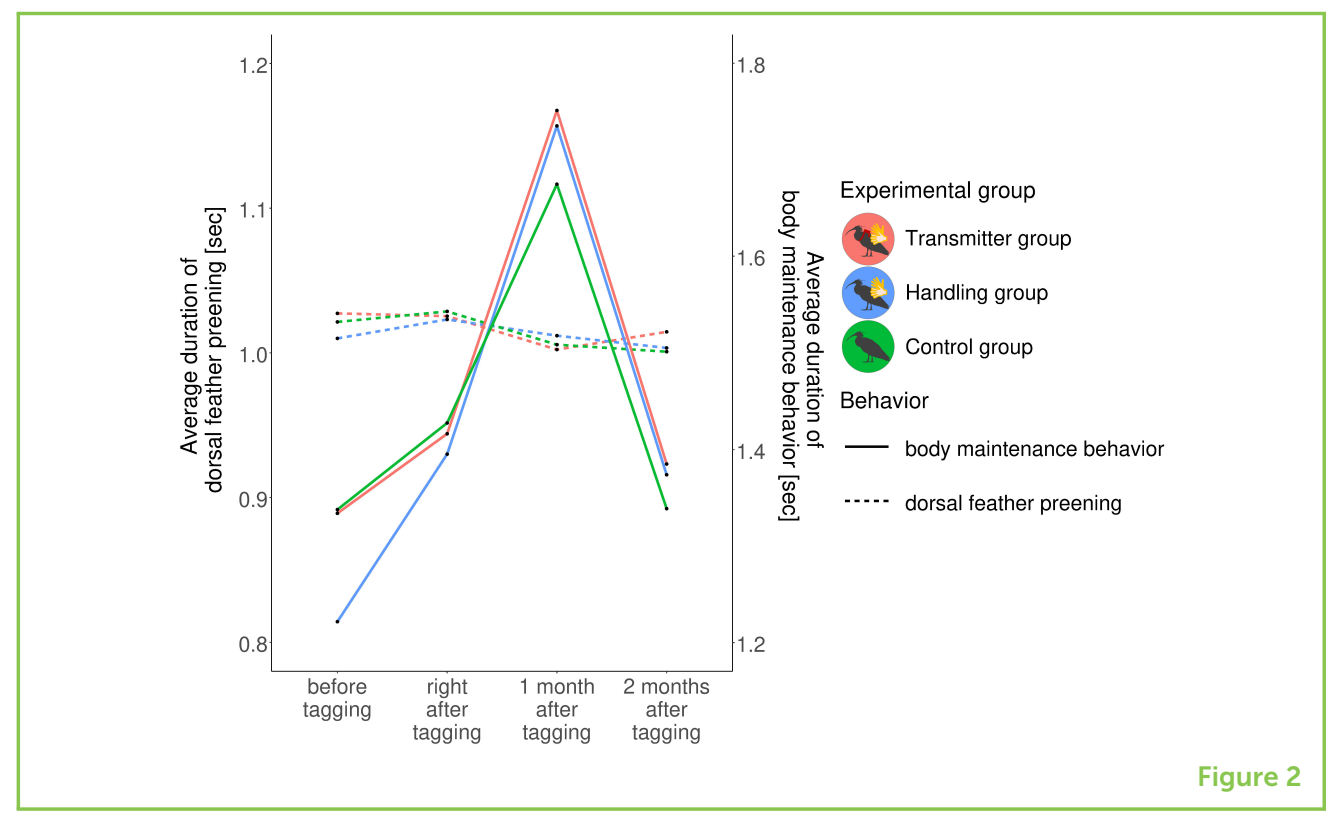

As friendly interactions between pair partners are important for reproduction, GPS-transmitter attachment might have consequences on the likelihood of tagged ibises reproducing. Luckily, our data showed that the tagged ibises' levels of friendly behavior returned to normal after 1 month after tagging.

We also saw some longer-term effects of tagging. Approximately 1 month after being tagged, the transmitter group had higher levels of corticosterone in their droppings compared with the handling and control groups (Figure 3). This could mean that the tagged birds were still stressed by carrying a GPS-transmitter, even though friendly behavior returned to normal. We saw that the corticosterone levels of all three experimental groups were similar at the end of the experiment (January), which means that this effect of tagging might be temporary.

We found no differences in the body weight between the transmitter and handling groups. This means that birds carrying a GPS-transmitter did not have to spend more energy compared to non-tagged birds.

\section{CONCLUSIONS}

In this study, we looked at the effect of GPS-transmitters on the behavior and bodily processes of northern bald ibis, an endangered bird species. We found no effects of the GPS-transmitters on many of the ibises' behaviors, including body maintenance behaviors. We did see a decrease in friendly behavior and an increase in corticosterone levels in droppings, but these factors were only temporarily affected by tagging. This study suggests that GPS-transmitters may not negatively impact birds and other animals over the long-term, as long as the 
Figure 3

Levels of

corticosterone

measured in the

droppings of the

various groups of northern bald ibises.

Measurements, in

nanograms of

hormone per gram of droppings, are shown

for transmitter,

handling, and control

groups. Corticosterone

levels were measured

at different phases of

the observation period,

shown on the $x$-axis.

You can see that 1

month after tagging the

transmitter group had

higher levels of

corticosterone in their

droppings compared

with the handling and

control groups. This

could mean that the

tagged birds were

temporarily more

stressed. Thus, it is

especially important in

endangered species to

measure

corticosterone levels in

tagged animals to keep

them healthy and

minimize possible

effects of

GPS-transmitters.

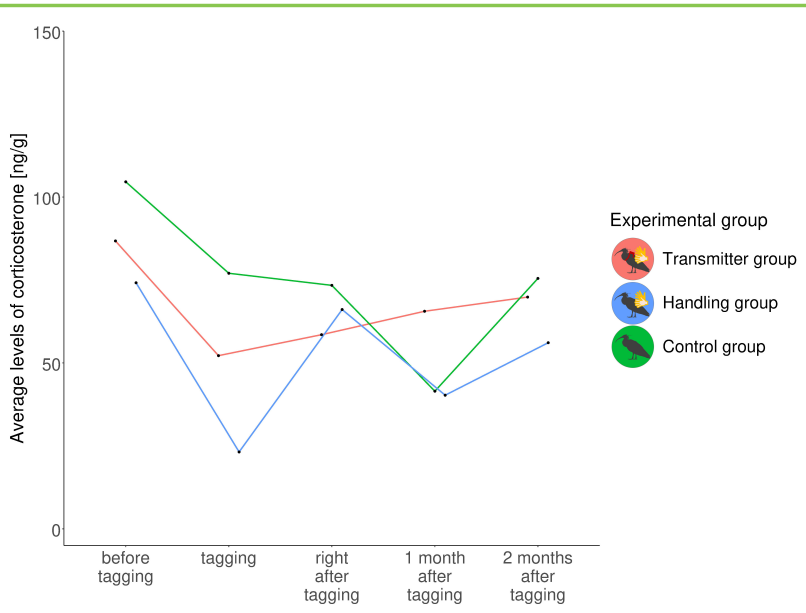

Figure 3

GPS-transmitters are properly designed. However, we feel that it is important for investigators to continue to measure corticosterone levels in tagged birds, to detect any possible increase in the birds' stress levels after they are tagged.

These findings will help researchers who are trying to conserve and protect endangered birds, since researchers want to keep the birds healthy and minimize the possible effects of GPS-transmitters. Using what we learned from these studies, we can employ these tiny backpacks to closely monitor endangered species, such as the northern bald ibis, to make informed decisions about how best to protect them-hopefully without stressing them out!

\section{ACKNOWLEDGMENTS}

Many colleagues contributed to the success of our study. We gratefully acknowledge Tanja Czerny, Katharina Buchegger, Julia Rittenschober, Julia Krejci, Johannes Gschwandegger, and Madelaine Leitsberger for helping in the field. We thank Felix Hirschenhauser for his contribution to writing this manuscript. Josef Hemetsberger, Matthias-Claudio A. Loretto and Kurt Kotrschal provided scientific assistance. The team of Elisa Pschernig at the Department of Behavioral and Cognitive Biology of the University of Vienna analyzed the droppings. The Verein der Förderer der Konrad Lorenz Forschungsstelle and the Herzog von Cumberland Stiftung provided permanent support.

\section{ORIGINAL SOURCE ARTICLE}

Puehringer-Sturmayr, V., Loretto, M. A., Hemetsberger, J., Czerny, T., Gschwandegger, J., Leitsberger, M., et al. 2020. Effects of bio-loggers on behaviour and corticosterone metabolites of Northern Bald Ibises 
(Geronticus eremita) in the field and in captivity. Anim. Biotelemetry 8:2. doi: 10.1186/s40317-019-0191-5

\section{REFERENCES}

1. Stuchbury, B. J. M., Tarof, S. A., Done, T., Gow, E., Kramer, P. M., Tautin, J., et al. 2009. Tracking long-distance songbird migration by using geolocators. Science 323:896. doi: 10.1126/science.1166664

2. Kays, R., Crofoot, M. C., Jetz, W., and Wikelski, M. 2015. Terrestrial animal tracking as an eye on life and planet. Science 348:aaa2478. doi: 10.1126/science.aaa2478

3. Tuckova, K., Zisser, B., and Kotrschal, K. 1998. Versuch der Ansiedlung einer ortsfesten Waldrapp-Kolonie an der Konrad Lorenz Forschungsstelle.

ÖKOL 20:3-14.

4. Phillips, R. A., Xavier, J. C., and Croxall, J. P. 2003. Effects of satellite transmitters on albatrosses and petrels. Auk 120:1082-90. doi: 10.2307/4090279

5. Pegoraro, K. 1992. Zur Ethologie des Waldrapps (Geronticus eremita L.). Beobachtungen in Volieren und im Freiland (Türkei, Marokko) (Doktorarbeit), University of Innsbruck, Innsbruck, Austria.

6. Palme, R., and Möstl, E. 1997. Measurement of cortisol metabolites in faeces of sheep as a parameter of cortisol concentration in blood. Int. J. Mamm.

Biol. 62:192-7.

SUBMITTED: 26 January 2020; ACCEPTED: 27 July 2020;

PUBLISHED ONLINE: 03 September 2020.

EDITED BY: Nathan M. Good, Michigan State University, United States

CITATION: Puehringer-Sturmayr V, Hemetsberger F and Frigerio D (2020) Tracking Birds: How a Little Backpack Could Affect the Life of a Wild Bird. Front. Young Minds 8:116. doi: 10.3389/frym.2020.00116

CONFLICT OF INTEREST: The authors declare that the research was conducted in the absence of any commercial or financial relationships that could be construed as a potential conflict of interest.

COPYRIGHT (c) 2020 Puehringer-Sturmayr, Hemetsberger and Frigerio. This is an open-access article distributed under the terms of the Creative Commons Attribution License (CC BY). The use, distribution or reproduction in other forums is permitted, provided the original author(s) and the copyright owner(s) are credited and that the original publication in this journal is cited, in accordance with accepted academic practice. No use, distribution or reproduction is permitted which does not comply with these terms. 

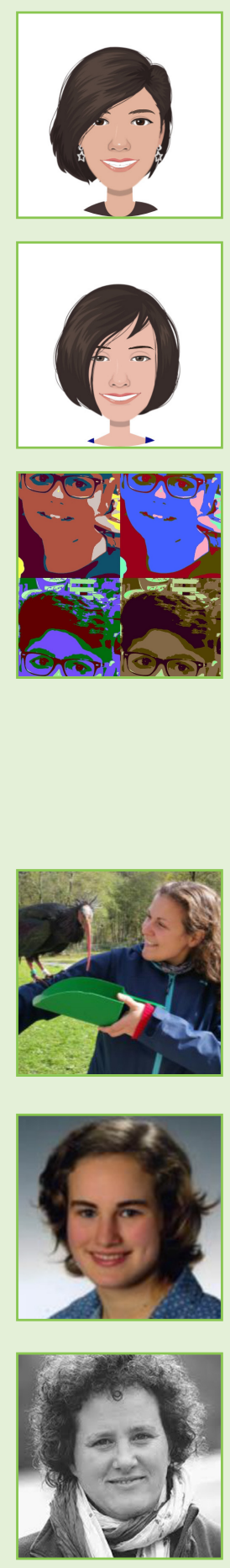

\section{YOUNG REVIEWERS}

\section{ISABEL, AGE: 9}

$\mathrm{Hi}$, I am Isabel and I am from Portugal. I am 9 and I like reading, writing, and music I have three cats and I like to learn about history. I have no idea of what I want to be when I grow up. I really like vegetables (and fruit).

\section{MARGARIDA, AGE: 12}

My name is Margarida, I am 12 years old and I like reading, climbing, and writing. I love science, especially anything about black holes and I have absolutely no idea what I want to do when I grow up. I also really like biology.

\section{SHASHIPREETHAM, AGE: 13}

Hello, my name is Shashi, I am 13 years old and I go to Penglais School. I enjoy playing football and basketball. My favorite subjects are maths and computers. I am currently studying year 8. I am a four times Guinness World Records holder in a game called Rocket League and my name is in 2018 Guinness World Record Gamers Edition.

\section{AUTHORS}

\section{VERENA PUEHRINGER-STURMAYR}

Verena Puehringer-Sturmayr is a behavioral biologist. Her main interests are animal behavior in combination with behavioral physiology, how individuals choose their habitats, and conservation. Currently, she is investigating factors affecting the habitat choice of the northern bald ibis.

\section{FRANCESCA HEMETSBERGER}

Francesca Hemetsberger is an undergraduate student. She is very curious and interested in several different topics, especially those related to the research world of her parents, who are both biologists.

\section{DIDONE FRIGERIO}

Didone Frigerio is a behavioral biologist. Her main interest is the relationship between sociality and body processes in group-living birds. She loves to work with greylag geese, even though northern bald ibises have also caught her attention recently. She applies citizen science as a research approach and involves pupils and citizens in her behavioral research. *didone.frigerio@univie.ac.at 